Rebecca Hale, Andrew Kilner, Rebecca Nucifora, Caitlin Plath, Elvis Wu, Xinyuan Zhang, Robert Faff* University of Queensland, Australia

\title{
Applications of 'Pitching Research' in an Emerging Economies Research Journal: Insights and Reflections
}

\author{
DOI: 10.7595/management.fon.2018.0012
}

\begin{abstract}
Research Question: Can we create a highly structured (but practical) abstract, which communicates the essential elements demanded by an expert scholarly reader? Motivation: A key aim of this journal is to enable "relevant information exchange and communication". Information overload means that readers are easily lost. Right at the start, poorly designed abstracts can fail to "hook" readers. Lost readers: this is bad for authors, editors and for the journal. What's new? While structured abstracts are not new, the "synergistic" combination of elements, combined with succinct guidance on content, is where the novelty lies. So what? Engaging readers in this way should lead to more journal activity - more readings, cites, submissions - and, ultimately, to an enhanced profile/reputation in the scholarly community. Idea: Building on Faff $(2015,2017)$ and Faff et al. (2017e) ["reverse engineering" and "pitch sparring"], we adapt the "Pitching Research" [PR] framework to create a structured and engaging abstract. Data: The "experimental" setting involves a sample of six high-performing non-research students, who signed up to an intense 4-week "research scholar" programme over Winter 2017, at the University of Queensland. Tools: The "Winter Scholars" are first taken through an "immersion treatment" on the PR framework. During this process, the students form three teams and each team is assigned an article to "spar" a reverseengineered pitch summary-abstract. There are several iterative rounds of abstract design. Findings: The original pitch is limited to 1,000 words, an initial condensed abstract aims for 400 words and the final version is modified to 350 words. Three examples of the final structured abstract are created in Accounting, Finance and Management, providing "soft" "proof of concept". Contribution: By creating a simple, focused and structured new abstract design adopted by this journal, we enhance the ability of the journal to meet its primary aim of enhancing "relevant information exchange and communication". Over time, with growing use and application in this journal, the reach of this contribution grows too. More generally, we argue that this novel abstract design increases awareness of the broader PR framework, helping readers and especially novice researchers better understand, describe and ultimately design their own scholarly research.
\end{abstract}

Keywords: pitching research; new research ideas; pitching; template; research proposal; novice researcher; reverse pitching; pitch sparring; pitching abstract.

JEL classifications: G00, M00, B40, A20, B00, C00, D00, E00, F00, H00, I00, J00, L00, Q00, R00, Z00

\section{Introduction}

This paper outlines two 'Reverse Engineering' applications of 'Pitching Research' (Faff, 2015 \& 2017a) designed to help readers and researchers better understand and describe academic literature. 'Reverse Engineering' is a concept explored by previous student scholars at The University of Queensland (Faff et al., 2017e). It is further investigated in the present paper with a new group of Winter Research Program students using a 'Pitch Sparring' approach. Further, the ' 400 Word PR Template Tool' was developed as a new application, designed by the Winter Research Scholar team. This was further refined to a slightly more focused version, that has since been newly adopted by the current journal as its ongoing article abstract design requirement.

The Winter Research Program at The University of Queensland offers non-research students the ability to develop their analytical, critical thinking and communication skills through research. Students are matched with 
a supervisor to work on a chosen research project, which provides synergies between research leaders and ambitious, high-performing students willing to learn. Students are offered a brief 'insight' into research and academia. In 2017, six Winter Scholars (all co-authors on the current paper) took on a project within the UQ Business School, to work with and develop applications of Faff's (2015, 2017a) 'Pitching Research' Tool. ${ }^{1,2}$

As stated on this journal's website, the aim of Management: Journal of Sustainable Business and Management Solutions in Emerging Economies (MJSBMSEE) is:

" ... to enable relevant information exchange and communication between scientists, researchers, managers, and people in different business areas, coming from universities, institutes, companies and public services. It represents an open discussion arena for new views, experiences and ideas concerning problems and management development tendencies in national and international perspective, with the aim of giving support to economic and social development."(emphasis added)

Two aspects of the above quoted journal aim have been highlighted since they provide two important general motivations for the current paper.

First, enabling relevant information exchange and communication is easier said than done. Information overload, the technology explosion and ever-growing demands on our time in the $21^{\text {st }}$ century mean that readers are impatient, "fickle" and easily distracted (Newman, 2010; Shatto \& Erwin, 2016). Central to the current paper is a simple but powerful framework; namely, Faff's $(2015,2017)$ pitching research tool, for igniting communication and knowledge exchange that arguably counters these three "demon" characteristics of our readers. To do this, the innovation developed and described herein is to "morph" Faff's $(2015,2017)$ original 1,000-word planning framework into a condensed reverse-engineered format, customised to operate as an actual journal abstract design. Indeed, it was applied as the newly adopted abstract design of MJSBMSEE, as part of the submission process (http://management.fon.bg.ac.rs/index.php/mng/about/submissions).

Second, giving support to economic and social development with the explicit focus is signalled in the journal's name: emerging economies while "emerging economies" is best illustrated by the "home" Serbian context, and actions to advance Serbian economic status toward this category (Stone, Yehoue\& Ishi, 2009; Vamvakidis, 2009; Soskic, 2015;Sun, Wang\& Luo,2018). Also, it is reflected both in the MJSBMSEE's journal archives of past articles and by its diverse Editorial Board; importantly, the "emerging economies" theme is credibly NOT limited to just Serbia. Historically, Serbia has a proud tradition of frontier scholarly research, with several prominent scientists of Serbian origin (e.g., Nikola Tesla, Milutin Milankovic, Mihajalo Pupin, Mihajlo Petrovic), but it suffered significant "political" setbacks over several decades in the $20^{\text {th }}$ century. The $21^{\text {st }}$ century heralds a time of careful "catch up", necessarily requiring speed while avoiding counterproductive "short cuts".

We argue that our paper aids this very cause. Through the agency of the new abstract format that we develop and explain, motivated by the information exchange and communication imperative, we primarily illustrate in the context of a prior article of this journal: Milinkovic et al. (2017). As illustrated in the abstract online (http://management.fon.bg.ac.rs/index.php/mng/article/view/17), and in the appendix, the abstract explores the relationship between students' life goals and their career preferences, in the Serbian setting. We argue that the new-format abstract enhances information exchange and communication, thereby helping to better engage future readers interested in research relevant to emerging economies. But crucially, even in the current journal, this impact goes beyond the Serbian setting - the research door is wide open, as reflected in the "new form" abstracts of recent articles of this journal: e.g., Lima et al. (2018) on the Brazillian Football League and Petrovic et al. (2018) looking at the EU digital agenda.

The remainder of this paper is organised as follows. Section 2 presents a brief overview of the "reverse engineering" $[\mathrm{RE}]$ application of the pitching research framework. Section 3 provides a brief coverage of the

\footnotetext{
${ }^{1}$ Since the launch of the original version of "pitching research" on SSRN 3.5 years ago, feedback received has helped to motivate the development of a range of supplementary material, support and initiatives, much of which is captured by twenty one companion papers, mostly available on SSRN: Faff (2016a, b, c); Faff (2017a, b, c); Faff (2018); Faff, et al., (2016a, b, c); Faff, et al., (2017a-2017j); Faff and Kastelle (2016); Hale, et al., (2017); Nguyen, et al., (2017); Teng and Faff (2017).

2 Interested readers are encouraged to view the short animation YouTube video that gives an entertaining and informative primer on the basic PR framework: http://bit.ly/2gZD6eG
} 
"sparring" application of the RE process. Section 4 considers the pitching research abstract application developed by the 2017 UQ Winter Research Scholars, while Section 5 presents the scholars' reflections of their experience in the programme. Section 6 concludes.

\section{Overview of PR 'Reverse Engineering' Process}

Faff developed the 'PR' framework in 2013, providing a structured template with which to clearly and comprehensively design and interpret research. It acts as a catalyst to condense and synthesise ideas during the research development phase and promotes efficiency and transparency in the research process. The two-page (1,000 word) pitching template begins with standard research 'preliminary' context-setting information: working title, research question, key papers and motivation for the study. Following this, the ' 3 2-1' countdown represents the core of the template, namely THREE (3) elements - idea, data tools; TWO (2) questions - 'What's new?' And 'So what?' The template ends with ONE bottom line for the study - its contribution.

The 'Reverse Engineering' process is based on the 'Pitching Research' template developed by Faff (2015). ${ }^{3}$ In order to complete the 'RE' exercise, the original 'PR' template requires two slight modifications. For the first item (A), the full, published reference was listed instead of a 'working title'; and for the final item (K), participants identified three key findings of the study, rather than highlighting potential 'other considerations'. Winter research participants were paired with another scholar based on compatible interests, and assigned a paper to reverse engineer into the PR framework. The use of cued sub-questions in each of the sections in the template provided helpful direction for students' first time using the tool. 'Reverse Engineering' is an application that utilises the PR framework to give students practice working with scholarly research. One team of students was assigned an article previously published in this journal: Milinkovic et al. (2017) and this team's original 'Reverse-Engineered' Pitch is shown in Figure 1. The online appendix (Appendix A) shows counterpart "RE" efforts produced by two other teams of Research Scholars relating to Albu et al. (2016) and Maricic et al. (2017).

\section{The 'Sparring' Process}

'Pitch Sparring' is an application of the 'PR' template, designed to facilitate discussion between "pitching" readers, in order to generate a better understanding of the PR framework. ${ }^{4}$ During the 2017 Winter Research Program, the paired 'PR sparring' exercise was completed as one overall task, integrating the previous 'three round' model outlined in Faff, Carrick, et al (2017a and 2017c). The approach comprised two phases for each item $(A)-(K)$ in the PR template: in the first phase, participants constructed an independent 'partial pitch', used during sparring and cross-collaboration in the second phase. Participants completed both phases for each item before progressing to the next. During the sparring exercise, participants were able to openly discuss differences in their approach and their ideas, in order to come up with a final response that was entered in the 'PR' reverse engineering template. In addition to the paired 'PR sparring' exercise, some of the scholars completed a 'PR sparring' exercise individually. Each scholar took a slightly different approach to complete this exercise and in some cases was able to make contact with an author of their chosen empirical paper in order to clarify any queries they had with regard to the paper and to gain feedback on their PR sparring' exercise. A summary of 'Pitch Sparring' notes for one of the teams have been included in the online appendix in Exhibit 1 (Appendix B) to illustrate the process.

\section{The "Pitching Research" Abstract Exercise}

\subsection{Initial Abstract Design}

A 400-word "Pitching Research" abstract was developed by the 2017 Winter Research Scholars under the leadership and direction of Professor Robert Faff, based on the existing "Pitching Research" template tool (Faff, 2015). The structure primarily follows the Pitching Research Template (Faff, 2015) with minor

\footnotetext{
${ }^{3}$ Interested readers are encouraged to view the short animation YouTube video that gives an entertaining and informative primer on the basic RE version of the PR framework: http://bit.ly/2DnxMbX

${ }^{4}$ Interested readers are encouraged to view the short animation YouTube video that gives an entertaining and informative primer on the "sparring" application of the PR framework: http://bit.ly/2rxxj4q
} 
adjustments. The "So What" and "What's New" sub-sections of the "PR" tool have been included as part of the "Motivation" for the structured abstract, along with the "3 Key Papers" sub-sections. The goal of Faff's "Pitching Research" 400-word abstract is to provide a more detailed and descriptive research overview to readers, without increasing complexity or compromising clarity. The structured nature of the abstract provides readers with a simple and direct approach to interpreting the contents, which allows for easier reading of the abstract material. During the Winter Research Program, students created a 'mock-up' 400 Word Abstract for each of the three 'Reverse Engineered' papers which followed the '400 Word Abstract' writing guidelines. The completed ' 400 Word Abstract' sections written by each of the three pairs are shown in the online appendix (Appendix C).

\subsection{Revised Abstract Designfor Journal Adoption}

After the completion of the UQ Winter Scholar Program in 2017, engagement occurred with the Editor of Management: Journal of Sustainable Business and Management Solutions in Emerging Economies. We discussed the potential for the 400 Word 'PR' Abstract framework to be combined with the writing guidelines for the journal. It was proposed that by integrating Faff's framework with the existing instructions, the journal could generate more direction and clarity for their authors. It was anticipated that the inclusion of a structured framework, specifically designed for abstract writing, would help guide the contribution of authors and academics.

In order to finalise a 400 Word 'PR' Abstract template for MJSBMSEE, there were a number of revisions that took place. Building on the initial version of the 400 Word Abstract guidelines, the finalised version remained relatively true to the 'Pitching Research' template form, with minor modifications. Suggested word lengths have been cut down in each section, reducing the overall word count in order to suit a traditionally less lengthy academic summary of 300-350 words. Discarding the 'Contribution' section was also discussed; however, it was deemed to play a significant role in understanding the value and real-world application for academic work. A finalised set of the writing guidelines for the 'Structured Abstract' adopted by the journal is shown in the online appendix (Appendix D).

\subsection{Examples of the "Pitching Research" Inspired Abstract Design Adopted by this Journal}

We offer three examples of the newly designed structured abstract. The first example is Lima et al. (2018) on the Brazilian Football League, displayed in Exhibit 1.The other two examples are: Milinkovic et al. (2017), which explores the relationship between students' life goals and their career preferences in the Serbian setting and Petrovic et al. (2018), looking at the EU digital agenda. These examples are available in the online appendix (Appendix E).

\section{Personal Scholar Reflections}

\subsection{Structure Abstract Exercise}

In assisting to develop the 'PR 400 Word abstract', a number of key strengths and potential limitations were identified while working with the first prototype. The first model proposed by Professor Faff followed the exact outline of the 'PR' template. Authors were to first explain a research question and outline the general motivation for the study. Following this, the Idea, collected Data and Tools used were described, as well as both the 'What's New?' and 'So What?' sections, before the key contributions of the study were considered. After completing an initial pilot for this abstract, the six scholars highlighted that the lengthier abstract model allowed for the inclusion of additional material improved information transparency without compromising clarity. However, the overlap of detail across a number of sub-sections rendered the model inefficient as it was not 'mutually exclusive and collectively exhaustive'.

As a result of this, a new model was proposed. The "So What" and "What's New" sub-sections of the "PR" tool have been included as part of the "Motivation" for the structured abstract, along with the " 3 Key Papers" sub-sections. This was done to avoid redundancy of information across the abstract. Although "So What" and "What's New" sub-sections are helpful in framing initial ideas and design considerations, an abstract is written post study completion. Upon obtaining results, what the study had planned to add, forms part of the motivation, whereas any new insights given by results are described as part of "Findings" in the structured abstract. The "Findings" section also provides an indication of what implications this may have in a 'realworld' context. 


\subsection{Individual Scholar Experiences in the Program}

Scholar 1: This research programme helped me understand and appreciate the often slow-moving nature of research, and the importance of patience - especially when co-authoring. The 'team-based' activities, such as the 'Pitch-Sparring' sessions allowed me to develop willingness and want to co-operate and understand the viewpoints of others. Individual writing tasks enabled me to gain experience writing in a clever and concise academic style. These skills will be of great value to me if I choose to continue to pursue academic research into the future.

Scholar 2: By working as a Winter Research Scholar on the Pitching Research, I have been able to gain a high-level knowledge about research in a short amount of time. As opposed to peers who worked on specific projects, I was able to understand more about how the research process develops from an initial idea all the way to devising an empirical framework and then to publication - whilst peers were tasked with lab experiments and data analysis. For an undergraduate I believe that is a great benefit and the experience has allowed me to have richer discussions with various postgraduate research students, many of whom are my respective tutors for undergraduate coursework. It has also given me ample time to begin to investigate various pathways for my own Honours Thesis which will begin eighteen months from now.

Scholar 3: Various aspects in the template became clearer when reverse engineering was performed for the second time. This included things as simple as highlighting important information and findings before inputting it into different sections of the template. More specifically, it became evident how and where to find relevant information for the 11 sections that form the template. Reflecting on my experience as a UQ Winter Research scholar, I have realised the challenges and benefits of research, and the endless career prospects it offers. More specifically, I believe the Pitching Research template can be used as a tool to better understand papers by breaking them down through reverse engineering, as well as its sole purpose, to help novice researchers commence their research project.

Scholar 4: After completing the 1000 word reverse engineer task Professor Faff asked us to rank how confidently we felt that we had captured all the dimensions of the assigned paper. This exercise was helpful as it enabled me to reflect on how well the 1000 word template was able to capture the paper and highlight all the key dimensions of the research paper. Overall, I felt that the Winter Research Program provided me with an invaluable experience, as I was able to develop critical thinking and presentation skills and the ability to write in a more succinct manner. After completing the reversed pitches I now appreciate how useful the Pitching Research Tool is, especially for novice researchers.

Scholar 5: Most importantly, I was exposed to how academics read articles and gained insight into how they generated their own ideas. This has been a valuable experience for me as I intend to complete a Ph.D. in the future. The template works well because it provides a general way for novice researches to generate their ideas and take their first steps in academic research. However, in my opinion, it doesn't fit for mature researchers because the template takes time and it does not provide a specific way for developing further research.

Scholar 6: The Winter Research Program at the University of Queensland was an amazing and unforgettable experience. The activities I participated in involved both individual and group work and enabled me to developed academic writing and presentation skills. Thanks to Professor Faff's guidance and my fellow scholars suggestions and feedback I felt like I gained more than I anticipated and I truly feel more confident about my future academic endeavours.

Conclusion

Following the direction of Professor Robert Faff, six 2017 UQ Winter Research Scholars utilized the 'Pitching Research' tools (Faff, 2015, 2017) as part of their research experience. They were encouraged to think critically and further develop both written and oral communication skills, working with academic literature. By way of practical examples, students examined, interpreted and synthesised the existing academic work. They completed both individual and group activities across a variety of project-based work. In addition to working with the pitching tool itself, students were given the opportunity to help develop additional learning applications for 'Pitching Research'. Establishing a condensed structured abstract framework was one of a number of key tangible takeaways from this Winter research experience. Evident through the reflections provided by the scholars, the project offered insight and practical guidance for working with research, assisted by the Pitching Research tool and its further applications. 


\section{REFERENCES}

[1] Albu, N., Calu, D.A. \&Guse, G.R. (2016) "The role of accounting internships in preparing students' transition from school to active life", Journal of Accounting and Management Information Systems, 15(1): 131-153

[2] Djamasbi S., Rochford J., DaBoll-Lavoie A., Greff T., Lally J., McAvoy K. (2016) Text Simplification and User Experience. In: Schmorrow D., Fidopiastis C. (eds) Foundations of Augmented Cognition: Neuroergonomics and Operational Neuroscience. AC 2016. Lecture Notes in Computer Science, vol 9744. Springer, Cham. DOI: 10.1007/978-3-319-39952-2_28

[3] Faff, R.(2015) "A simple template for pitching research", Accounting and Finance, 55: 311-336. DOI: $10.1111 /$ acfi.12116

[4] Faff, R. (2016a)"Mapping "pitching research" tasks into the RSD7 framework: A pedagogic perspective", available at SSRN: http://ssrn.com/abstract=2724451 DOI: $10.2139 /$ ssrn.2724451

[5] Faff, R. (2016b) "The "pitching research" concept: 2015, a year in review", available at SSRN: https://ssrn.com/abstract=2721528_DOI: 10.2139/ssrn.2721528

[6] Faff, R. (2016c) “Learning from 'pitching research' competition winners: Insights and reflections”, available at SSRN: https://ssrn.com/abstract=2891650DOI: 10.2139/ssrn.2891650

[7] Faff, R. (2017a) "Pitching research ${ }^{\circledR}$ ", Version 15 (or beyond) available at SSRN: http://ssrn.com/abstract=2462059DOI: $10.2139 /$ ssrn.3018939

[8] Faff, R. (2017b) Pitching research ${ }^{\circledR}$ : A comprehensive resource center supplement, available at SSRN: https://ssrn.com/abstract $=3018939 D O I$ : 10.2139/ssrn.3018939

[9] Faff, R. (2018) "Pitching Research: "Qualitative Cousins" and the "Extended Family"”, Accounting \& Finance, forthcoming. DOI: 10.1111/acfi.12348

[10] Faff, R.\&Kastelle, T. (2016) "Pitching research for engagement and impact", available at SSRN: http://ssrn.com/abstract=2813096 DOI: 10.2139/ssrn.2813096

[11] Faff, R., Godfrey, K. \&Teng, J. (2016a) "Pitching research evolution: An illustrative example on the topic of 'innovation and financial dependence'”, available at SSRN: https://ssrn.com/abstract=2776959 DOI: $10.2139 /$ ssrn.2776959

[12] Faff, R., Li, Y., Nguyen, B. \& Ye, Q. (2016b) "Pitching research: A pilot experiment with UQ Winter scholars", available at SSRN:https://ssrn.com/abstract=2816233 DOI: 10.2139/ssrn.2816233

[13] Faff; R., Wallin, A.,Brosnan, M., Carrillo, N.,Darmawan, D.,Dorris, A., Groen, M.,Listiani, N., Maxwell, V., Orole, F., Pham, A., Salehudin, I., Simons, M., To, D., Tsoi, J., Wong, C., Woods, K., Yossa, N. \&Zhaunerchyk, K. (2016c) "Fantasy pitching II: Star Wars vs. Pokemon vs. R\&D vs. Uber", available at SSRN: http://ssrn.com/abstract=2827425 DOI:10.2139/ssrn.2827425

[14] Faff, R., Ali, S., Atif, M., Brenner, M., Chowdhury, H., Crudas, L., Joubet, A., Malik, I., Nagar, V., Mi, L., Pullen, T., Siegrist, M., Smythe, S., Stephenson, J., Zhang, B. \& Zhang, K. (2017a) "Fantasy pitching", Accounting and Management Information Systems, 16(2), 360-379

[15] Faff, R., Babakhani, N., Carrick, R., Chen, A.,Dallest, K., Daunt, L., Escobar, M., Foley, G., Gill, C., Khong, M., Liu, M., Mahmud, D., McCullough, J.,Ndugwa, N., Nguyen, B., O’Brien, S., Orole, F., Qureshi, A., Rad, H.,Rekker, S., Shahzad, K., Smith, M., Tran Le Nghi, T., Tunny, W. \&Wallin, A. (2017b) "Motivating postgrad research students to pitch their ideas: What have we learned from 'pitching research' competitions at UQ?", available at SSRN: https://ssrn.com/abstract=2899942_DOI:10.2139/ssrn.2899942

[16] Faff, R., Babakhani, N.,Dallest, K., Daunt, L., Foley, G., O’Brien, S. \& Tran Le Nghi, T. (2017c) "Book of pitches: UQAPS 2016 pitching research competition final", available at SSRN: https://ssrn.com/abstract=2967736DOI: 10.2139/ssrn.2967736

[17] Faff, R., Baladi, J.,Buce, D., Du Plessis, G., Du Plessis, C., Dwyer, B., Honey, K., Melton, D., Oktaviani, F., Shen, S., Steele, L., Suhodo, D., Tanner, M., Unger, C., Wong, S., Xu, J. \& Zou, S. (2017d) "Fantasy Pitching IV: Batman, Donald Duck, Fast Food, Superpowers, Self-Determination", available at SSRN: https://ssrn.com/abstract=2939489DOI: 10.2139/ssrn.2939489

[18] Faff, R., Carrick, R., Chen, A., Escobar, M.,Khong, M., Nguyen, B. \& Tunny, W.(2017e) "Pitching research: A reverse-engineer "Sparring" experiment with UQ Summer research scholars", Available at SSRN:https://ssrn.com/abstract=2903811 DOI: 10.2139/ssrn.2903811

[19] Faff, R., Carrick, R., Chen, A., Escobar, M.,Khong, M., Nguyen, B. \& Tunny, W. (2017f) "Fantasy pitching III: UQ Summer research scholars - the role of "money" in the 21st Century", available at SSRN: https://ssrn.com/abstract=2906617 DOI: 10.2139/ssrn.2906617

[20] Faff, R., Carrick, R., Chen, A., Escobar, M.,Khong, M., Nguyen, B. \& Tunny, W. (2017g) "UQ Summer research scholar program: Insights and reflections from the pitching research "I-Templates" team", available at SSRN: https://ssrn.com/abstract=2919027DOI: 10.2139/ssrn.2919027

[21] Faff, R., Gill, C., McCullough, J., Noh, J-E., Mahmud, S.N.D.,Ndugwa, N., Eats, P. \&GhorbaniGorji, S. (2017h) "Book of pitches: UQAPS 2015 pitching research competition final", available at SSRN: https://ssrn.com/abstract $=2953842$ 
[22] Faff, R., Lay, J. \& Smith, M. (2017i) "PoW! Using social media to leverage research visibility - "Pitch of the Week" posts in Linkedln", available at SSRN: https://ssrn.com/abstract=2894069 DOI: 10.2139/ssrn.2894069

[23] Faff, R., Shao, X.,Alqahtani, F., Atif, M.,Białek-Jaworska, A., Chen, A.,Duppati, G., Escobar, M.,Finta,M., Li, Y., Machado, M.,Nguyen, B., Noh, J-E.,Sakawa, H.,Vaportzis, E., Widyawati, L., Wijayana, S.,Wijesooriya, C., Ye, Q.\& Zhou, Q.(2017j) "Increasing the discoverability of non-English language research papers: A reverse-engineering application of the pitching research template", available at SSRN: https://ssrn.com/abstract $=2948707$. DOI: $10.2139 /$ ssrn.2948707

[24] Hale, R., Kilner, A., Nucifora, R., PlathC., Wu, E., Zhang, X. \& Faff, R. (2018) "Applications of 'Pitching Research': Insights and Reflections from the 2017 UQ Winter Research Scholars", available at SSRN: https://ssrn.com/abstract=3130029DOI: $10.2139 /$ ssrn.3130029

[25] Lima, E., de Oliveira, V., Pavlovic, V., Fischer, C., Machado, A. \&Tertuliano, I. (2018). The Influence of Expenditures in Football Industry Results: Case Study of the Brazilian Football League, Management: Journal of Sustainable Business and Management Solutions in Emerging Economies, 23(1), 112.DOI:10.7595/management.fon.2018.0006

[26] Maricic, M., Zornic, N., Pilcevic, I. and Dacic-Pilcevic, A. (2017). ARWU vs. Alternative ARWU Ranking: What are the Consequences for Lower Ranked Universities?. Management: Journal of Sustainable Business and Management Solutions in Emerging Economies, 22(1),1-14.DOI:10.7595/management.fon.2017.0002

[27] Milinkovic, I., Kovacevic, I., \&Mihailovic, D. (2017). What Do Freshmen Want? Career Path Preferences Among Students, Management: Journal of Sustainable Business and Management Solutions in Emerging Economies, 22(1), 37-45. DOI:10.7595/management.fon.2017.0006

[28] Newman, M. Z. (2010). New media, young audiences and discourses of attention: from Sesame Street to 'snack culture'. Media, Culture \& Society, 32(4), 581-596. DOI: 10.1177/0163443710367693

[29] Nguyen, B., Faff, R. \&Haq, M. (2017)"Pitching research lite: A reverse-engineering strategy for finding a new research direction", available at SSRN: https://ssrn.com/abstract=2909549 DOI: 10.2139/ssrn.2909549

[30] Petrovic, M., Bojkovic, N., Stamenkovic, M. \&Anic, I. (2018). A sensitivity analysis of ELECTRE based stepwise benchmarking for policy: The case of EU digital agenda, Management: Journal of Sustainable Business and Management Solutions in Emerging Economies, forthcoming. DOI: 10.7595/management.fon.2018.0003

[31] Shatto, B., \& Erwin, K. (2016). Moving on from millennials: Preparing for generation Z. The Journal of Continuing Education in Nursing, 47(6), 253-254. DOI: 10.3928/00220124-20160518-05

[32] Soskic, D. (2015). Inflation targeting challenges in emerging market countries: The case of Serbia. Economic annals, 60(204), 7-30.DOI:10.2298/EKA1504007S

[33] Stone, M. M. R., Yehoue, M. E. B., \& Ishi, K. (2009). Unconventional central bank measures for emerging economies (No. 9-226). International Monetary Fund. WP 09/226.

[34] Sun, J., Wang, S. L., \& Luo, Y. (2018). Strategic entry or strategic exit? International presence by emerging economy enterprises. International Business Review, 27(2), 418-430. DOI:10.1016/j.ibusrev.2017.09.009

[35] Teng, J.\& Faff, R. (2017) "A "snowballing" pedagogic strategy for pitching research: An illustrative example in finance", available at SSRN: https://ssrn.com/abstract=2906127 DOI: 10.2139/ssrn.2906127

[36] Vamvakidis, A. (2009). Convergence in emerging Europe: Sustainability and vulnerabilities. Eastern European Economics, 47(3), 5-27.DOI: 10.2753/EEE0012-8775470301

Received: 2017-05-11

Accepted: 2018-06-13

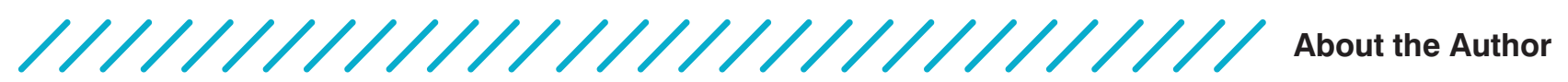

Rebecca Hale
University of Queensland, Business School
rebecca36hale@gmail.com

Rebecca Hale is a BBusMan/BSc (Honours) student at the University of Queensland

(UQ). She has a passion for learning and development and a growing interest in consulting and organizational psychology. Her research interests include; learning and development, management, inter-group relations, leadership and change management. Rebecca completed a Winter Research Scholarship program with UQ in 2017 and has continued her passion for research with Honours in Psychology. In 2017, Rebecca was admitted to the Faculty of Business, Economics and Law Dean's Honour Roll for outstanding academic excellence.

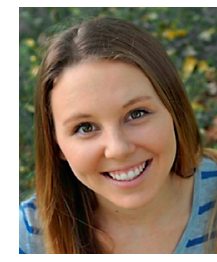


Andrew Kilner

University of Queensland, Business School andrew.kilner@uq.net.au

Andrew Kilner is a student at the University of Queensland, studying a Bachelor of Advanced Finance and Economics (Honours). Andrew has experience within asset management and economic consulting. The Pitching Research program was Andrew's first experience in academic research and he hopes to complete a thesis within the Finance Honours program through UQ Business School in 2019.

\section{Rebecca Nucifora \\ University of Queensland, Business School rebecca.nucifora@uq.net.au}

Rebecca Nucifora is a student at the University of Queensland. She currently studies a Bachelor of Business Management (majors in Business Economics and Human Resources) and a Bachelor of Commerce (major in Accounting). Her research interests include business risk and controls, restructuring organisations and people management.

$$
\begin{array}{r}
\text { Caitlin Plath } \\
\text { University of Queensland, Business School } \\
\text { cplath95@gmail.com }
\end{array}
$$

Caitlin Plath is a graduate of the University of Queensland where she obtained a Bachelor of Economics and a Bachelor of Commerce. Caitlin is currently working as an analyst at Deloitte in the Assurance and Advisory team where she plans on completing her $\mathrm{CA}$ in the coming years.

\section{Wenhao (Elvis) Wu \\ University of Queensland, Business School adl.wawh@gmail.com}

Wenhao Wu is a Bachelor student at the Faculty of Business, Economics \& Law. He is a novice researcher working on the Finance area. His research interests include Banking and Finance, Investment and Portfolio Analysis, and Risk Management.

\section{Xinyuan Zhang \\ University of Queensland, Business School xinyuan.zhang.ny@gmail.com}

Miss Xinyuan Zhang graduated from the University of Queensland with a Bachelor of Commerce. During the undergraduate period, she was an exchange student in Boston

College. Her research interests include market management, risk management, corporate valuation, and investment and portfolio analysis. She has had a number of internships for a variety of public and national securities institutions and cross-border banking. She will soon begin studying Applied Analytics at Columbia University with a concentration on data analytics in modern internet finance.

\section{Robert Faff \\ University of Queensland, Business School r.faff@business.uq.edu.au}

Robert Faff has an international reputation in finance research: securing 14 Australian

Research Council grants ( $>\$ 4$ million); $>300$ refereed journal publications; career citations >11,000; h-index of 53 (Google Scholar). His particular passion is nurturing and developing the career trajectories of early career researchers. Robert has supervised more than $35 \mathrm{PhD}$ students to successful completion and examined $50 \mathrm{PhD}$ dissertations. Building on a 35-year academic career, his latest focus is "Pitching

Research" [https://ssrn.com/abstract=2462059], now gaining great traction domestically and worldwide as exemplified by: >12,200 SSRN downloads; >250 pitching talks/events; at 37 Australian universities; and spanning $>50$ countries.
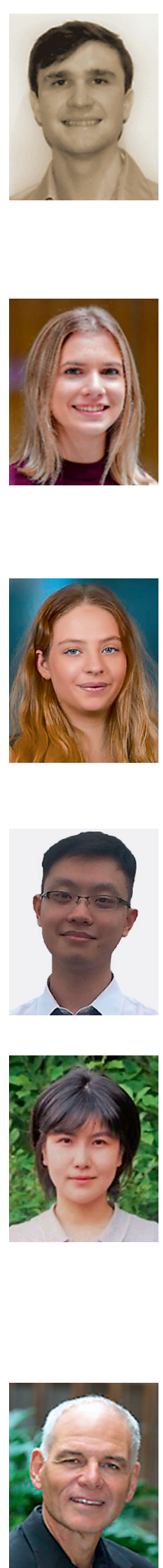


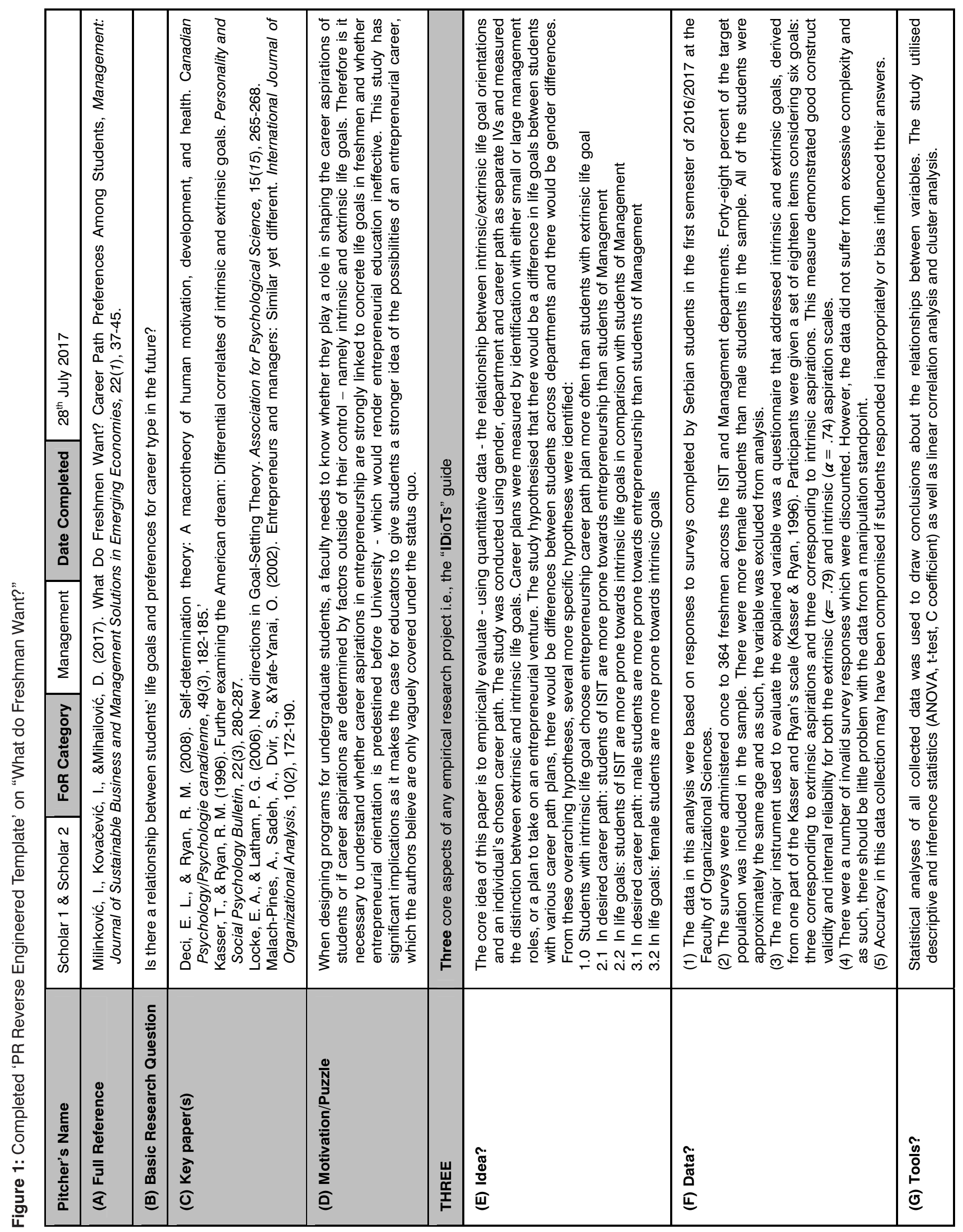




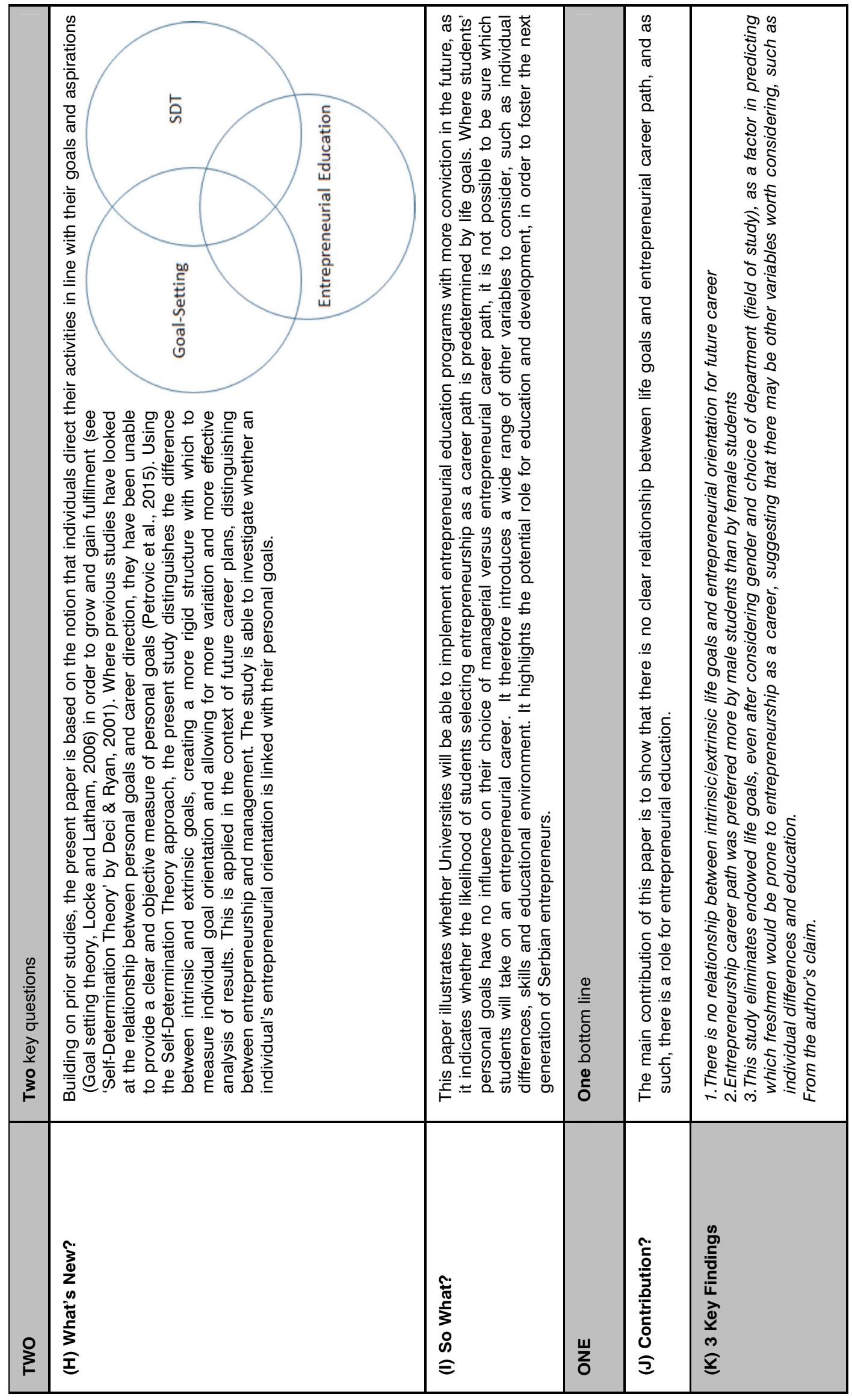


Exhibit 1: Example of New-form Structured Abstracts

\section{The Influence of Expenditures in Football Industry Results: Case Study of the Brazilian Football League}

Abstract: Reserarch question: The paper investigates the influence of football clubs investments on their
performance in the first division of the Brazilian league. Motivation: Given that football is the most important
sport in Brazil, representing a cultural symbol of the country, a better understanding of it becomes necessary.
Therefore, it is necessary to investigate the financial amounts involved in the management actions to try to
understand the influence of the investments that the clubs put into marketing and championships improvement
and, consequently, to be able to delineate the relation between investment and success in football. Idea: In this
perspective, the central hypothesis of this study is that the clubs that present the highest expenditures on soccer
will also present the best classifications, since these expenses are related to better training conditions and
salaries, which may contribute to the recruitment of the best athletes. Data: The study was conducted using the
data collected over the Internet, the data disclosed by clubs. Only the clubs belonging to the first division were
used, a total of 19 clubs, divided into 3 groups, according to the investment value in football. Tools: This study
presents descriptive and inferential analyzes, since the qualitative-quantitative approach was assumed as a way
of understanding the data. Assuming the number of clubs participating in the study, we chose non-parametric
inferential analyzes in the intra- and inter-group evaluations, using the alpha value of 0.05 as a criterion. Findings:
The results showed that clubs in groups G1 and G2 had similar expenditure dynamics, while G3 group clubs had
a slight swing. In addition, clubs in groups G1 and G2 had the largest amounts of expenditures, while G3 clubs
had the lowest expenditure during the period analyzed. These results demonstrated that the clubs of the G1 and
G2 groups achieved the best positions in the championships, corroborating the research hypothesis.
Contribution: One can conclude that the investment of the clubs directly influences the classification in the
championships, large investments obviously being necessary to conquer the championship. However, this study
has some limitations, such as sample size (19 teams only). Therefore, we emphasize the need for new studies.

Key Words: Football, Brazilian football league,Football Clubs, Classification of clubs, Sports administration.

JEL Classification: Z23 